\title{
Historical Biogeography: Evolution in Time and Space
}

\author{
Isabel Sanmartín
}

Published online: 21 June 2012

(C) Springer Science+Business Media, LLC 2012

\begin{abstract}
Biogeography is the discipline of biology that studies the present and past distribution patterns of biological diversity and their underlying environmental and historical causes. For most of its history, biogeography has been divided into proponents of vicariance explanations, who defend that distribution patterns can mainly be explained by geological, tectonic-isolating events; and dispersalists, who argue that current distribution patterns are largely the result of recent migration events. This paper provides an overview of the evolution of the discipline from methods focused on finding general patterns of distribution (cladistic biogeography), to those that integrate biogeographic processes (event-based biogeography), to modern probabilistic approaches (parametric biogeography). The latter allows incorporating into biogeographic inference estimates of the divergence time between lineages (usually based on DNA sequences) and external sources of evidence, such as information on past climate and geography, the organism fossil record, or its ecological tolerance. This has revolutionized the discipline, allowing it to escape the dispersal versus vicariance dilemma and to address a wider range of evolutionary questions, including the role of ecological and historical factors in the construction of biomes or the existence of contrasting patterns of range evolution in animals and plants.
\end{abstract}

Keywords Dispersal $\cdot$ Distribution patterns $\cdot$ Ecological factors $\cdot$ Extinction $\cdot$ Historical processes $\cdot$ Vicariance

I. Sanmartín ( $ه)$

Real Jardín Botánico, RJB-CSIC,

Plaza de Murillo 2,

28014 Madrid, Spain

e-mail: isanmartin@rjb.csic.es

\section{Introduction}

Thanks to advances such as better exploration techniques, satellite cartography, or the use of geographic information systems (GIS), global patterns of biodiversity distribution are now fairly well understood. Conversely, the causal factors and processes underlying such patterns are still debated. Biogeography is the discipline of biology that attempts to reconstruct the patterns of distribution of biological diversity and to identify the processes that have shaped those distributions over time. Why are organisms distributed where they are today? How have faunas and floras assembled through time? Traditionally, biogeography has been divided into two different approaches (Morrone and Crisci 1995): ecological biogeography, the study of the environmental factors shaping the distribution of individual organisms at local spatial scale, and historical biogeography, which aims to explain the geographic distribution of organisms in terms of their evolutionary history. The latter usually deals with longer time scales (millions of years), larger spatial scales (e.g., continental landmasses), and the distribution patterns of species or higher taxa. This distinction, however, has become blurred in recent years. For example, the young discipline of phylogeography (Avise 2000), often considered a part of historical biogeography, works with intermediate time scales of thousands of years and the distribution patterns of biological populations, such as those formed after the retreat of the last glaciations at the end of the Quaternary. In addition, historical biogeography has begun lately to incorporate ecological information into biogeographic reconstructions through techniques like ecological niche modeling (Lieberman 2000; Stigall and Lieberman 2005) and new analytical statistical methods (Ronquist and Sanmartín 2011). 


\section{Vicariance vs. Dispersal: The Case of the Ratite Birds}

Biogeography is a very old discipline, dating back to the time when the first naturalist explorers, such as Alexander von Humboldt (1805), were intrigued by the fact that regions with similar climates like the Mediterranean Basin and Chile in South America exhibited faunas with similar physiognomies (life forms) but in which the inhabiting species were very different. Conversely, regions such as Africa and South America separated by large geographic barriers like the Atlantic Ocean show faunas of similar composition (Cox and Moore 2010). One of the best examples of this type of disjunct geographic distribution is that of ratites, a primitive group of birds (Palaeognatha) that includes the ostriches, cassowaries, emus, rheas and kiwis. This clade is distributed in all major southern continents (Fig. 1a), but how did these flightless birds come to be confined to a distribution scattered across different continents, now separated by thousands of miles of ocean?

Two alternative biogeographic processes have been proposed (Fig. 1b): dispersal - the ancestor of the group was originally distributed in one of the areas, the "center of origin," from which it dispersed to the other areas by crossing a geographic barrier (e.g., the Southern Hemisphere ocean basins, Fig. 1b left); vicariance - the group ancestor was distributed in a widespread area, then covering all its present distribution, which became fragmented by successive geographic barriers; this geographic division was followed by allopatric speciation, so that each member now survives in an isolated continent. The best example is the breakup of the ancient supercontinent of Gondwana during the Mesozoic-Cenozoic, which has often been argued to explain austral disjunct distribution patterns such as that of ratites (Fig. $1 \mathrm{~b}$ right). In the dispersal explanation, the barrier predates the geographic disjunction, whereas in the vicariant explanation, the appearance of the barrier causes the geographic division, so it must be of the same age as the resulting allopatric speciation event.

Naturally, these processes are not mutually exclusive: for example, the formation of the Panama isthmus between North and South America at the end of the Tertiary (3.5 million years ago) was simultaneously a vicariant event—by isolating marine organisms between the Atlantic and Pacific Oceans - and a dispersal event, since it established a new migration route between North and South America for terrestrial mammals, the "Great American Biotic Interchange" (Simpson 1980). But for many decades, these two explanations were viewed as competing hypotheses in historical biogeography, with proponents of one or another engaged in a polarized and sometimes heated debate (review in Cox and Moore 2010 and Lomolino et al. 2006). The current tendency is to accept both dispersal and vicariance explanations as equally likely hypotheses and use other information sources (e.g., the fossil record, information on past climates and geography, or the ecological tolerance of the group) to discriminate between them (Stigall and Lieberman 2006; Ronquist and Sanmartín 2011). In this review, I use the example of ratites to show how incorporating new sources of evidence into biogeographic reconstructions has allowed researchers to address a wider range of evolutionary questions than the simple search for congruent distribution patterns.

\section{Dispersalism and Centers of Origin}

For centuries, dispersal was the dominant explanation supported by a static concept of Earth and life. Darwin's theory of evolution (1859) changed this immutable view of species by identifying the mechanism, natural selection, by which organisms evolve into new species. But Darwin and his contemporaries, like Wallace (1876), still believed on the idea of geological stability, according to which the position and size of continents had not changed over time. New species evolved in a limited area, a "center of origin," from which they dispersed to other regions over the same pattern of world geography that we see today (Cox and Moore 2010; Lomolino et al. 2006). This view was challenged by "extensionists" such as Joseph Dalton Hooker (1844), who argued that long-distance dispersal across persistent barriers was unlikely, and instead continents must have been connected in the past by tracts of dry land and nowsubmerged landbridges over which organisms dispersed. Darwin and Wallace's idea of dispersal from a center of origin continued to be dominant through the first half of the twentieth century, represented by the "New York school of zoographers," of which Matthew (1915), Darlington (1957), and Simpson (1953) were the most important proponents. The introduction of the theory of plate tectonics in geology, and especially the arrival of cladistics (see below), led to a new approach, Phylogenetic Biogeography (Brundin 1966; Hennig 1966) that departed from the narrative dispersal scenarios of the past. Although it was still based on the idea of "dispersal" and "centers of origin," it was also the first approach to use information about the evolutionary relationships of organisms (in the form of a tree or cladogram) as the basis to infer their biogeographic history. For example, it assumed that in every speciation event, the species that retained the ancestral ("plesiomorphic") characteristics stayed closer to the original area, while the most derived ("apomorphic") species was the one that dispersed (Crisci et al. 2003; Cox and Moore 2010). Brundin (1966) was also pioneer in using geological information to interpret biogeographic histories (Lomolino et al. 2006).

Two criticisms have been raised against the dispersalist approach to biogeography, especially by cladistic 
a)

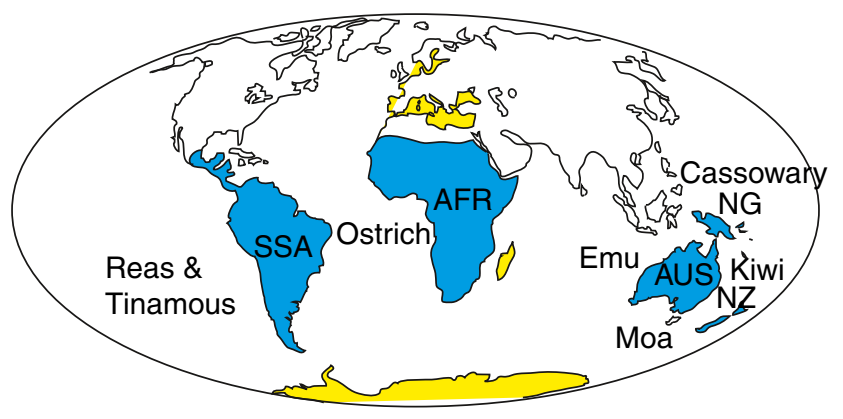

b)
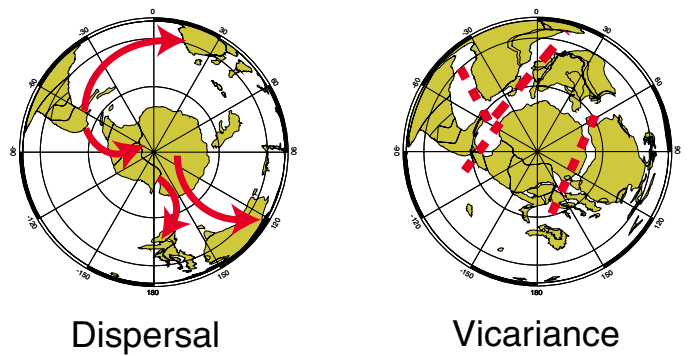

c)

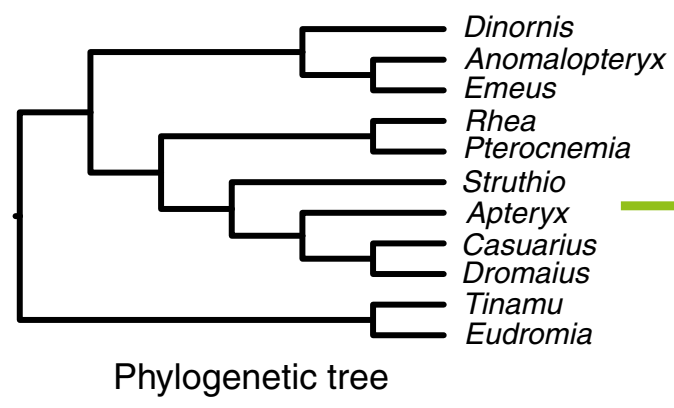

Fig. 1 Biogeographic history of the ratite birds (ostriches, emus, reas, etc.). a Current geographic distribution of extant and extinct ratite genera; areas in yellow (Antarctica, Europe) harbor fossil remains but no extant species. b Two alternative hypotheses to explain this disjunct distribution: recent, ocean-crossing dispersal events (left) or ancient, tectonic-isolating vicariance events (right). c A cladistic biogeographic analysis comprising three steps: (left) DNA-based phylogeny representing the relationships among ratite genera and their relatives: tinamous (adapted from Pereira and Baker 2006); (center) a taxon-area cladogram is constructed by replacing the taxon names in the phylogeny with the areas where they occur; (right) a cladistic biogeographic

biogeographers (see below): (a) Lack of scientific basis: Since any distribution pattern can be explained by invoking a sufficient number of dispersal events, dispersal-based hypotheses cannot be refuted scientifically within a rigorous hypothetic-deductive framework. Also, if we accept dispersal as a possible explanation for disjunct patterns, vicariance explanations would never be inferred (Platnick and Nelson 1978; Morrone and Crisci 1995). (b) Lack of predictive power: Dispersal-based hypotheses are lineage-specific, idiosyncratic scenarios that can only explain the biogeographic history of individual lineages (e.g., Brundin 1966) but cannot provide a general theory to explain how organisms with different ecologies and dispersal abilities came to occupy the same biogeographic regions and to exhibit similar distribution patterns (Croizat et al. 1974; Nelson and Platnick 1981; Humphries and Parenti 1986). As we will see below, this is not necessarily true, and dispersal can sometimes generate congruent distribution patterns similar to those expected from vicariance. method (Brooks Parsimony analysis, Brooks 1990) is used to derive an "area cladogram" showing the relationships among the areas in Fig. 1a based on their shared endemic taxa. This area cladogram presumably represents the history of biotic connections between the areas of endemism for the ratite genera: tinamous (Tinamu, Eudromia), extinct moas (Dinornis, Anomalopteryx, Emeus), reas (Rhea, Pterocmemia), ostriches (Struthio), kiwis (Apteryx), cassowaries (Casuarius), and emus (Dromaius). Adapted from Sanmartín (2009). Paleomaps 0 million years (left) and 100 million years (right) adapted from ODSN (http://www.odsn.de/odsn/services/paleomap/paleomap.html)

\section{Vicariance and Cladistic Biogeography}

In the second half of the twentieth century, two scientific revolutions contributed to the appearance of a new paradigm in historical biogeography. The first revolution was the surge of cladistics (Hennig 1966), a new method to reconstruct evolutionary relationships among organisms based on shared, derived biological characteristics ("synapomorphies"). When competing hypotheses of evolutionary relationships exist, those that imply the minimum number of changes or ad hoc assumptions are preferred - the principle of "parsimony" or "Occam's razor" (Cox and Moore 2010; Lomolino et al. 2006). The second revolution was the development in the 1960s of the "theory of plate tectonics." The Earth's outer layer, the lithosphere, is divided into rigid rocky plates comprised of continental and oceanic crust that move over the surface of the Earth by sliding on the plastic upper layer mantle, the athenosphere. The idea that species could passively ride on the continents as they split and 
dispersed across the surface of the Earth led to the concept of "vicariance," summarized on the Italian botanist Leon Croizat's (1958) famous sentence: "Life and Earth evolve together," meaning that geological barriers evolve together with biotas (Cox and Moore 2010).

Cladistic vicariance biogeography (Rosen 1978; Platnick and Nelson 1978; Nelson and Platnick 1981; Wiley 1988) was born from the fusion of cladistics and Croizat's concept of vicariance (Fig. 1c). In the vicariant model, an ancestral area is divided by the appearance of successive geographic barriers. Since each geographic division would have been followed by allopatric speciation, one can reconstruct the sequence of vicariance events from the sequence of cladogenetic (speciation) events in the phylogeny of the lineages endemic to the area (Fig. 1c, left). A cladistic biogeographic analysis starts with the construction of an "area cladogram," in which the name of taxa in the phylogeny is replaced with the areas where they occur (Fig. 1c, center). If every taxon is endemic to one area and every area harbors one taxon, the construction of area cladograms is trivial. But often, area cladograms include widespread taxa (taxa present in more than one area), such as the ratite genus Casuarius in Australia and New Guinea, or redundant distributions (several taxa occurring in the same area), such as the kiwis and moas in New Zealand (Fig. 1c, center). This introduces ambiguity in the inference of the area cladogram because these areas may occupy different positions in the area cladogram depending on which relationships are allowed between the areas occupied by the non-endemic taxa. Cladistic biogeographers use different methods that differ in the way they treat these ambiguous data to derive a "resolved" area cladogram in which each area is represented only once (Fig 1c, right). These include Component Analysis (Nelson and Platnick 1981; Page 1990), Brooks Parsimony Analysis (BPA, Brooks 1990; Wiley 1988), Tree Reconciliation (Page 1994), and Paralogy-free subtrees (Nelson and Ladiges 1996) and more recently, Phylogenetic Analysis for Comparing Trees (PACT, Wojciki and Brooks 2005) and Threearea-cladistics (Ebach et al. 2003); see Crisci et al. 2003 and Morrone 2009 for a more detailed explanation on these methods. An area cladogram is a hierarchical, branching pattern of relationships that groups areas based on their shared endemic taxa and which presumably reflects the history of biotic connections between the areas of endemism for the group of organisms analyzed. For example, "sister" areas that form a clade in the area cladogram, such as Australia and New Guinea, would have shared a more recent biotic connection in the past for ratite birds; that is, the barrier between these two areas was formed more recently than other barriers with the remaining areas. Furthermore, by comparing area cladograms of several groups of organisms that inhabit the same region, one might find general biogeographic patterns - a "general area cladogram"- that presumably reflect the relationships among the areas of endemism based on their shared biotas (Nelson and Platnick 1981; Wiley 1988). For example, Crisci et al. (1991) compared the area cladograms of numerous animal and plant lineages from South America and found two different biogeographic regions: northern "tropical" South America was related biogeographically to North America, whereas southern "temperate" South American showed closer biotic links to Australia.

In comparison with the narrative dispersal scenarios that had earlier dominated the field, cladistic biogeography represented a huge leap forward because it provided for the first time an analytical framework with which to reconstruct the biogeographic history of lineages and biotas. Taxa that shared similar phylogenetic and distribution patterns were assumed to have shared a common biogeographic history; i.e., they were part of the same ancestral biota that became divided by geologic or climatic vicariant isolating events. Thus, unlike dispersalist hypotheses, vicariance hypotheses could be tested by searching for congruence in phylogenetic and distribution patterns among different organisms (Humphries and Parenti 1999; Parenti 2007). Cladistic biogeography also helped to move the discipline from a taxon-based approach centered on reconstructing the evolutionary history in space and time of individual lineages (e.g., Brundin 1966) toward a comparative "area biogeography" approach that aims to understand global distribution patterns through the comparison of area cladograms (Crisci et al. 1991; Humphries and Parenti 1999).

Nevertheless, as with dispersalism before, cladistic biogeography became in time a too "reductionist" explanation because it denied dispersal of any major role in generating global biodiversity patterns. Dispersal was considered a rare and random phenomenon that affected individual lineages but did not produce congruent distribution patterns (Humphries and Parenti 1999). Similarly, dispersal histories -because they were idiosyncratic and lineage-specific events - could not be addressed within a hypothetic-deductive framework like cladistic biogeography. This view of dispersal as a unique event instead of a pattern-generating process is challenged by the case of oceanic islands of volcanic origin, such as the Hawaiian Archipelago, which could only have been colonized by over-water dispersal. Funk and Wagner (1995) found that patterns of island colonization in these islands were highly congruent across multiple lineages, proceeding from one island to the next along the island chain. Similarly, Sanmartín et al. (2008) inferred highly concordant, non-random colonization patterns across numerous organisms endemic to the Atlantic Canary Islands.

So far, we have been discussing about the traditional form of dispersal that involves individual species moving over a geographic barrier (Humphries and Parenti 1986), also termed "jump" or "random" dispersal (Ronquist 1998). But there is another type of dispersal, "dispersion" or "range 
expansion," in which an individual species expands its geographic range in response to the disappearance of a previous geographic (dispersal) barrier. This type of dispersal has been termed "geodispersal" (Lieberman and Eldredge 1996) or "predicted dispersal" (Ronquist 1998) when it involves congruent, temporally correlated range expansion in independent clades. Unlike jump dispersal, it is not lineage-specific but usually connected to geological or global climatic events that cause several different lineages to expand their ranges congruently. Therefore, as expected from vicariance, geodispersal events can give rise to biogeographic patterns that are congruent across groups with different ecologies and dispersal abilities (Lieberman 2000, 2003). One example is the closing of an ocean barrier previously separating two continents, such as the Turgai Strait between Europe and Asia 30 million years ago, which led to episodes of range expansion occurring simultaneously in multiple animal clades (Sanmartín et al. 2001).

Unlike jump dispersal, cladistic biogeographers accept dispersion as a necessary process to explain how ancestors obtained their widespread distribution prior to the first vicariance event (Humphries and Parenti 1999). In addition, new cladistic methods such as PACT and modified Brooks Parsimony analysis (Lieberman and Eldredge 1996; Lieberman 2000), from the so-called "Phylogenetic Biogeography II" school (Lomolino et al. 2006), recognize geodispersal as a process that results in congruent distribution patterns across multiple lineages like vicariance, and which therefore might be inferred through a general area cladogram approach. But the distinction between jump dispersal and geodispersal (or land dispersal) is not always clear. The breaking or forming of land connections in plate tectonics is a gradual process, so there may be a temporal transition from land dispersal to jump dispersal with other types of dispersal falling in between. For example, the land connection over Antarctica that allowed marsupials to migrate from South America to Australia before the Antarctic continent became glaciated went through several phases (Woodburne and Case 1996; Sanmartín 2002): land dispersal was possible through the South Tasman Rise until the Early Paleocene (64 million years), followed by "stepping-stone" island dispersal across the shallow marine seaway separating Australia and Antarctica until the Early Eocene (52 million years); eventually, fully marine conditions were established with the opening of the South Tasman Sea 35 million years ago, after which only jump dispersal was possible (Sanmartín 2002). Finally, land dispersal not only requires a geological connection, e.g., a land bridge, but that the environmental conditions along the bridge are within the ecological limits of the dispersing organisms (Wiens and Donoghue 2004). A "filter corridor" involves land dispersal with a more selective connection restricted to organisms exhibiting the right ecological tolerance. For example, migration across Beringia during the Quaternary glaciations was restricted to cold adapted, tundra organisms (Sanmartín et al. 2001).

A second criticism against cladistic biogeography is that it ignores processes in the biogeographic inference: the area cladogram is inferred without any reference to the underlying biogeographic events. Cladistic methods have been termed "pattern-based" (Ronquist 2003; Sanmartín 2007) because they are allegedly process-free. They focus on finding patterns of relationships among areas of endemism, which are later interpreted in terms of events, and this sequence-first discovering a pattern, then inferring its cause - is the foundation of the cladistic biogeographic approach (Ebach et al. 2003; Parenti 2007). Cladistic biogeographic methods interpret congruence between distributional patterns as the result of vicariance, whereas any case of incongruence between the general area cladogram and the individual patterns is explained by additional processes, such as jump dispersal, speciation, or extinction (Brooks 1990; Humphries and Parenti 1999). One problem with this approach is that usually several different processes can explain the same biogeographic pattern (see below), so it is difficult to compare alternative biogeographic scenarios using cladistic methods (Sanmartín 2007).

Phylogenetic biogeographic methods such as PACT and modified BPA depart from this standard approach in that in addition to searching for a general area cladogram, the "backbone" of the tree, which is interpreted as resulting from vicariance or geodispersal events, they attempt to infer other processes that are lineage-specific. These unique events that affect single lineages can include extinction, postspeciation range expansion, jump dispersal, or failure to speciate in response to a vicariant event (Wojciki and Brooks 2005; Lieberman 2000, 2003; Stigall and Lieberman 2005). Still, these methods share the goal with standard cladistic approaches of producing "area cladograms," hierarchical patterns of biotic relationships between areas of endemism that are interpreted in terms of processes (e.g., Maguire and Stigall 2008), but which are inferred without explicit reference to an underlying statistical process model (see below).

Finally, as seen above, geodispersal events caused by continental collision can create patterns of area relationships in which areas and their biotas become connected instead of splitting as in the vicariance model. Most regions actually conform to a "reticulate" pattern with alternative cycles of area collision (geodispersal) and area splitting (vicariance), as barriers form and close over time. For example, during the Mesozoic era, the Northern Hemisphere continents were joined into a paleocontinental configuration, AsiamericaEuramerica, that was very different from the current one in which we find the separate continents of North America and Eurasia (Fig. 2; Sanmartín et al. 2001). This complex reticulate scenario cannot be represented by a single area 
a) $150 \mathrm{Ma}$
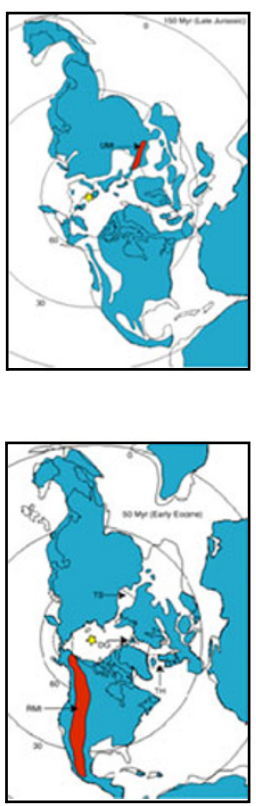

$50 \mathrm{Ma}$
$80 \mathrm{Ma}$
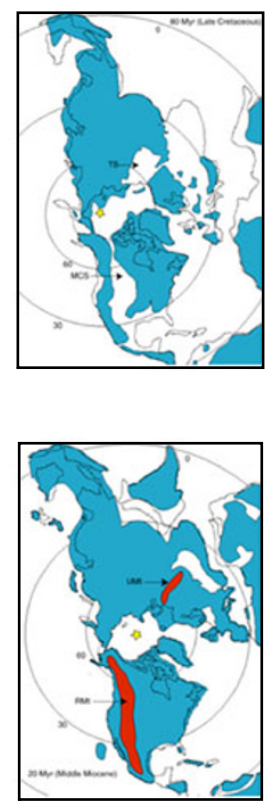

$20 \mathrm{Ma}$

b)

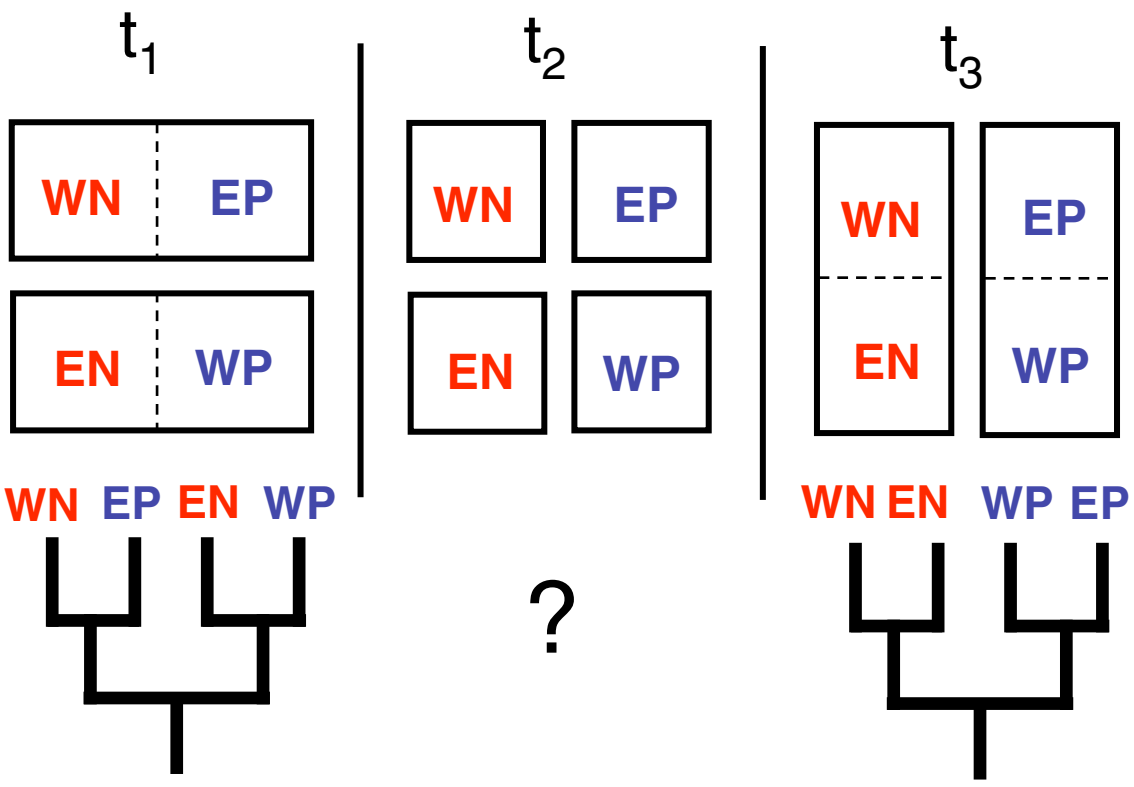

Fig. 2 Reticulate biogeographic history: a Geological history of the Northern Hemisphere, showing how northern landmasses joined and split repeatedly over time as barriers (epicontinental seas) and connections (landbridges) arose and fell. b Scheme representing the difficulties to represent such a history into a single pattern of relationships between areas of endemism or "area cladogram." In the Mesozoic, the northern landmasses were joined into the paleocontinents of

cladogram because the hierarchical relationships between areas change over time (Fig. 2). Phylogenetic biogeographic methods such as modified BPA (Lieberman 2000) address this problem by inferring two different area cladograms, one reflecting the vicariance (geographic division) events and the other the geodispersal (area collision) events. If the vicariance and geodispersal cladograms exhibit congruent topologies, it is assumed that cyclical events had produced the observed biogeographic pattern (Maguire and Stigall 2009).

\section{Event-Based Biogeography: Integrating Processes and Patterns}

Event-based methods were born as a response to the limitations of cladistic biogeography as explained above (Page 1995; Ronquist 1997, 1998, 2003). These methods use a deterministic cost-model approach in which each event or biogeographic process (e.g., dispersal, vicariance) is assigned a given cost according to its likelihood of occurrence. Figure 3 shows an event-based reconstruction of the biogeographic history of ratites. Besides dispersal and
Euramerica (EN-WP) and Asiamerica (WN-EP), whereas the present continental configuration between North America (EN-WN) and Eurasia (WP-EP) was attained during Cenozoic times. During some time periods, the four landmasses were isolated. Abbreviations: $E N$ and $W N$ : Eastern and Western North America divided by the Rocky Mountains; $E P$ and $W P$ : Asia and Europe separated by the Ural Mountains. Adapted from Sanmartín et al. (2001) and Sanmartín (2007)

vicariance, the biogeographic cost model includes two additional processes (Fig. 3a): extinction, the disappearance of a lineage from part of its ancestral distribution, and duplication ("within-area speciation"), which is sometimes equated to sympatric speciation or to allopatric speciation in response to a temporary dispersal barrier affecting a single organism lineage (Ronquist 2003). By fitting the organism phylogeny to an area cladogram reflecting the relationships between the areas of endemism (Fig. 3b), we can obtain the biogeographic reconstruction (Fig. 3c) with the minimum cost in terms of the events that need to be postulated to explain the observed distribution pattern (Ronquist 2003; Sanmartín 2007).

Notice that an event-based reconstruction not only specifies the set of events (dispersal, extinction, duplication, and vicariance) that have led to this pattern of biogeographic distributions, but also their relative timing (Fig. 3c). It suggests that the ancestor of ratites and tinamous (Tinamu, Eudromia) was present in the landmasses that once formed part of East Gondwana before they broke apart (New Zealand, South America, Australia-New Guinea), and that the divergence of moas (Dinornis, Anomalopteryx, Emeus) and rheas (Rhea, Pterocnemia) was the result of vicariance, 
a)

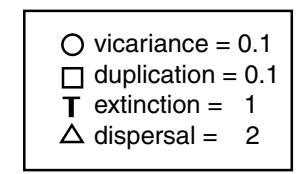

Cost matrix b)

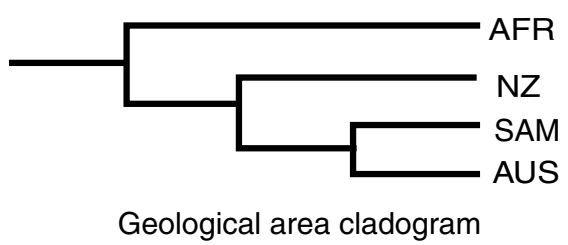

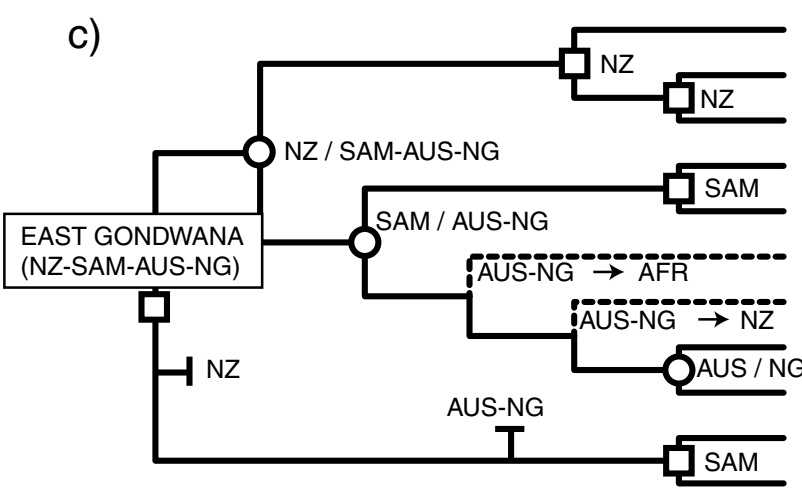

Event-based reconstruction
Dinornis d)

Anomalopteryx

Emeus

Rhea

Pterocnemia

Struthio

Apteryx

Casuarius

Dromaius

Tinamu

Eudromia d)

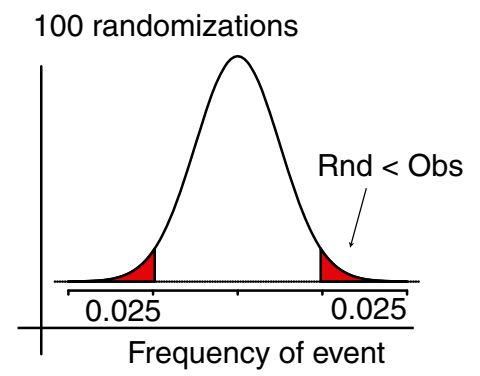

Fig. 3 Event-based reconstruction of the biogeographic history of ratites. Given a cost-based biogeographic model in which each biogeographic event is assigned a cost (a), and a geological area cladogram specifying the relationships between the areas of endemism, i.e., the breakup sequence of the southern continents from Gondwana (b), it is possible to infer how much the biogeographic history of ratites may be explained by geological vicariance and how much by additional

geologically isolating events (the breakup of connections between New Zealand and South America and East Antarctica); by contrast, the occurrence of ostriches (Struthio) in Africa and kiwis (Apteryx) in New Zealand was the result of dispersal events that took place after these landmasses broke away from Antarctica (Fig. 3c). In the ratite example, the area cladogram represents the geological sequence of Gondwana breakup (Fig. 3b), and the reconstruction in Fig. 3c indicates how much the biogeographic history of ratites can be explained by this sequence of vicariant isolating events. In other cases, the area cladogram can be inferred by searching for the pattern of area relationships that best explains the phylogeny and terminal lineage distributions or, in other words, the pattern of area relationships that produces the biogeographic reconstruction with the minimum cost in terms of the inferred biogeographic events.

The main difference between this event-based reconstruction and the cladistic biogeographic approach in Fig. 2 is that processes are not inferred "a posteriori" from the area cladogram, but instead the inference of processes is directly tied to the inference of biogeographic patterns through the cost-matrix model. A different biogeographic model with different costs might result in a different pattern of area relationships and a different set of biogeographic events. This explicit connection between the process-based model processes, such as dispersal, extinction, and duplication (see text for an explanation). d The significance of the inferred reconstruction can be tested by comparing the frequency of events in the original phylogeny against a distribution of frequencies obtained by randomizing the distributions in the original phylogeny 100 times. Abbreviations as in Fig. 1. Adapted from Ronquist and Sanmartín (2011)

and the expected patterns makes it possible to compare alternative biogeographic hypotheses or scenarios within a statistical inference framework (Sanmartín 2007). For example, one can compare the observed frequency of biogeographic events with a null distribution obtained from randomizing the distributions in the original phylogeny to test whether the observed patterns are phylogenetically conserved (Fig. 3d).

An obvious difficulty of the event-based approach is how to decide the cost of the biogeographic events. The most common method is to use a parsimony-based optimality criterion and choose costs that maximize the chances to recover "phylogenetically conserved" distribution patterns, that is, distribution patterns that do not change from ancestor to descendants and are conserved along the phylogeny. This is equivalent to the most parsimonious ("minimum change") explanation for the observed biogeographic pattern. Given that vicariance is a process that produces congruent ("conserved") distribution patterns across lineages, one option is to maximize the number of vicariance events by assigning this process a negative cost or benefit (Page 1995). Another option is to penalize those biogeographic events that break up the geographic association between ancestor and descendants (Ronquist 2003; Sanmartín et al. 2007). Under this criterion, dispersal and extinction must have a higher 
cost than vicariance and duplication because they both generate distribution patterns that are not phylogenetically conserved. For example, through dispersal the descendants may come to occupy a different range than the ancestor, such as in the case of kiwis (Apteryx in Fig. 3c), which are endemic to New Zealand but whose ancestor is inferred to have been present in Australia-New Guinea. Similarly, through extinction, one of the two descendants gets extinct in part of the ancestral range, breaking the geographic association between ancestor and descendants, such as the extinction of the ancestor of ratites in New Zealand after an initial "duplication" event in East Gondwana (Fig. 3c).

One of the most popular event-based methods is dispersal-vicariance analysis (DIVA, Ronquist 1996, 1997). DIVA uses a cost-matrix approach in which extinction and dispersal events are assigned a higher cost in relation to vicariance and duplication. But unlike all other methods, it is not based on finding an area cladogram but on mapping area distributions onto the phylogeny and inferring the ancestral areas at cladogenetic events by minimizing the number of dispersal and extinction events. Because vicariance events are not ordered into a strictly bifurcating, splitting pattern like an area cladogram, DIVA is especially powerful for inferring reticulate biogeographic scenarios, such as the Northern Hemisphere (Fig. 2), in which areas join and split in different combinations over time with the arising and falling of barriers (Sanmartín et al. 2001; Donoghue and Smith 2004).

Although initially developed for inferring the history of single lineages ("taxon biogeography"), DIVA and other event-based methods can be used to infer general biogeographic patterns by summarizing frequencies of dispersal and vicariance events across multiple groups distributed in the same set of areas. This has provided some novel insights on the relative role of dispersal and vicariance in shaping general biogeographic patterns. For example, event-based meta-analyses of the Northern Hemisphere (Sanmartín et al. 2001; Donoghue and Smith 2004) and Southern Hemisphere (Sanmartín and Ronquist 2004) biotas suggest that animals and plants showed fundamentally different biogeographic patterns, with animal distributions more likely to reflect ancient vicariance events and plant distributions more often shaped by recent dispersal events. This has been explained by the fact that plants are better colonizers due to the higher ability of plant seeds to disperse, whereas animals exhibit higher resilience or the ability to cope with the changing environments; this might have important implications for the construction of biomes (Donoghue and Smith 2004; Sanmartín 2007). Event-based meta-analyses also contributed to the recognition in biogeography of the concept of "concerted dispersal," by which jump dispersal (i.e., dispersal crossing a barrier as opposed to geodispersal), if channeled by abiotic factors such as prevailing winds or ocean currents, can generate congruent, non-random distribution patterns across multiple co-distributed lineages similar to those expected from vicariance (Sanmartín and Ronquist 2004). For example, many New Zealand plant species have their sister group in Australia, even though New Zealand separated from Australia ca. 80 million years ago. Paleobotanical evidence (Pole 2001) and event-based reconstructions (Sanmartín et al. 2007) suggest that these New Zealand plants dispersed from Australia by long-distance dispersal after the two continents broke apart, probably driven by the eastwardmoving West Wind Drift.

Proponents of cladistic biogeography often criticize event-based methods because they "over-simplify" the data by imposing a particular model, i.e., the cost-matrix approach (Ebach et al. 2003; Brooks 2005). Others argue that biogeographic inference must focus on finding patterns, not looking for ad hoc explanatory processes (Parenti 2007). But as seen above, the explicit connection between processes and the expected patterns make it easier for event-based methods to evaluate alternative biogeographic hypotheses (Crisp et al. 2011). A more serious criticism against these methods lies in the inference of processes that are not tied to speciation, such as extinction. Unlike cost constraints in relation to geology are introduced (Ronquist 1996; Sanmartín 2007; Nylander et al. 2008; Kodandaramaiah 2010). Also, complete extinction events, in which a lineage disappears from the entire ancestral range, or full dispersal events, in which one lineage leaves the ancestral range to colonize a different area without speciating, cannot be inferred with event-based methods because these events do not leave a trace in the phylogeny. For a dispersal or extinction event to be inferred, it must be tied to a speciation event, that is, dispersal and extinction must leave at least one descendant in the original area to be traceable from the phylogeny. In fact, this problem affects all biogeographic methods that are parsimony-based, including cladistic biogeography (see below). Lieberman (2002) showed that extinction events may erase the signal of vicariance and create artificially incongruent distribution patterns when no fossil information is included in a cladistic biogeographic analysis.

Parsimony in Biogeography Perhaps the most serious limitation of event-based and cladistic biogeographic methods is their reliance on the principle of parsimony for biogeographic inference (reviewed in Sanmartín 2010). Parsimony is a "minimization" criterion - i.e., the "most parsimonious" explanation is the one that implies the minimum number of changes in the geographic range that are needed to explain the current lineage distributions. Therefore, parsimony-based reconstructions tend to underestimate the frequency of events such as dispersal and extinction that break the geographic association between ancestor and descendants. 
Time is also a difficult dimension to incorporate within the parsimony framework. The branches in an area cladogram or an event-based reconstruction reflect the relative order of branching (vicariant) or fusing (geodispersal) events (Lieberman 2003; Sanmartín et al. 2007) but not the degree of divergence between lineages or the time since cladogenesis. This stands in contrast with the vicariance paradigm that has a clear temporal component: it predicts that clades showing disjunct distributions must be older than the geographic barrier that fragmented their geographic range. Thus, comparing the age of the barrier with the time of cladogenesis should allow discriminating between dispersal and vicariance explanations. The perils of ignoring time in biogeography are demonstrated by the phenomenon of "pseudocongruence": when two groups show similar biogeographic patterns but with a different temporal origin, and are therefore unlikely to have been caused by the same biogeographic events (Upchurch and Hunn 2002; Donoghue and Moore 2003). Parsimony-based methods cannot truly discriminate between pseudocongruence and true "shared biogeographic history," which implies both topological and temporal congruence between biogeographic patterns (Donoghue and Moore 2003). This is a serious flaw of these methods because, as we saw above, biogeographic barriers are often cyclical and the same barrier might have arisen at different points in time (Lieberman 2000; Sanmartín et al. 2001).

Despite these drawbacks, parsimony-based methods, such as event-based or phylogenetic cladistic approaches are still a valuable option when time-calibrated branch lengths are not easily available. For example, they are often used in paleontological research (Lieberman 2000; Stigall and Lieberman 2006; Maguire and Stigall 2008; Prieto-Marquez 2010). Moreover, time can be incorporated indirectly in DIVA by separating events into time bins (Sanmartín et al. 2001), or in phylogenetic paleobiogeography (Maguire and Stigall 2008), by using a "temporally calibrated cladogram" in which time is given by the stratigraphic age and position of the fossil lineage in the phylogeny.

\section{Parametric Biogeography: Integrating Processes, Patterns, and Time}

The role of time in biogeography became more relevant with the introduction of the concept of the "molecular clock." The vast majority of DNA-changes (mutations) are neutral from the point of view of fitness, and therefore tend to accumulate over time. If calibrated with independent information such as the fossil record, the molecular divergence between two organisms can be used to infer their time of divergence (Cox and Moore
2010). Many recent molecular studies have used this correlation to discriminate between dispersal and vicariance explanations and to show that dispersal had a larger role in generating distribution patterns than traditionally assumed (Renner 2004; Sanmartín and Ronquist 2004; Cook and Crisp 2005; de Queiroz 2005). This molecular approach to biogeography has been criticized by some biogeographers (Heads 2005) because of the inherent errors associated with the molecular clock: violated assumptions of rate constancy, incompleteness of the fossil record, use of molecular clocks from distantly related taxa, difficulties to assign the fossil to a particular clade in the phylogeny (e.g., "stem" or "crown" node), etc. Many of these criticisms have become less relevant, however, with recent developments in phylogenetic dating methods that permit relaxing the molecular clock assumption, i.e., allowing rate heterogeneity across lineages (e.g., Drummond and Rambaut 2007), or incorporating the uncertainty in the fossil calibration through the use of probabilistic approaches (Ho 2007).

In recent years, new parametric statistical approaches have been developed in biogeography to incorporate the time dimension into the inference and as a response to what was perceived as the major weakness of the parsimony approach (Ree and Sanmartín 2009; Sanmartín 2010). These methods are termed "model based" or "parametric" because they are based on statistical models of range evolution, whose parameters ("variables") are biogeographic processes such as dispersal, range expansion, or extinction. Range evolution-i.e., the change in geographic range from ancestor to descendants - is modeled as a stochastic process that changes along the branches of the phylogenetic tree according to a probabilistic "Markov-chain" model. At the heart of a Markovchain model, there is a "matrix of transition probabilities" (Fig. 4a) that determines the instantaneous rate of change from one state to another. In biogeographic models, the states of the Markov process are the set of discrete geographic areas that form the distribution range of the group (A, B, and AB; Fig. 4a), and the parameters of the model are biogeographic processes that change the geographic range of the species, such as range contraction (extinction, $E_{\mathrm{A}}$ ) or range expansion $\left(D_{\mathrm{AB}}\right.$, Fig. $\left.4 \mathrm{a}\right)$. By letting the model evolve along the branches of the phylogeny, which here represent the time since cladogenesis (Fig. 4b), we can estimate the rates (probability) of occurrence of the biogeographic processes $\left(D_{\mathrm{AB}}, D_{\mathrm{BA}}\right.$, $\left.E_{\mathrm{A}}, E_{\mathrm{B}}\right)$ and infer the most probable ancestral ranges at every cladogenetic event (Fig. 4c; Sanmartín 2010).

Compared to previous approaches, these methods offer several advantages (Sanmartín 2010). The most obvious is that the frequency (rate) of events can be estimated from the data, instead of assigned a cost a priori using ad hoc criteria, 
a)

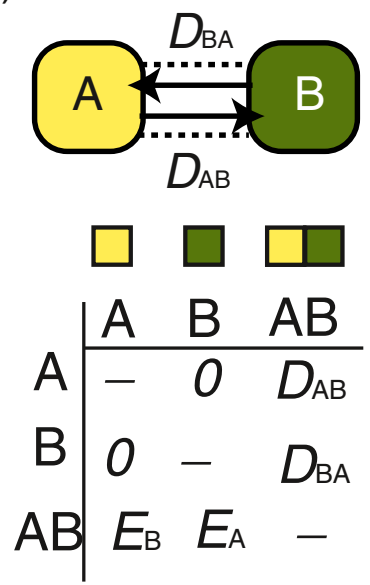

b)

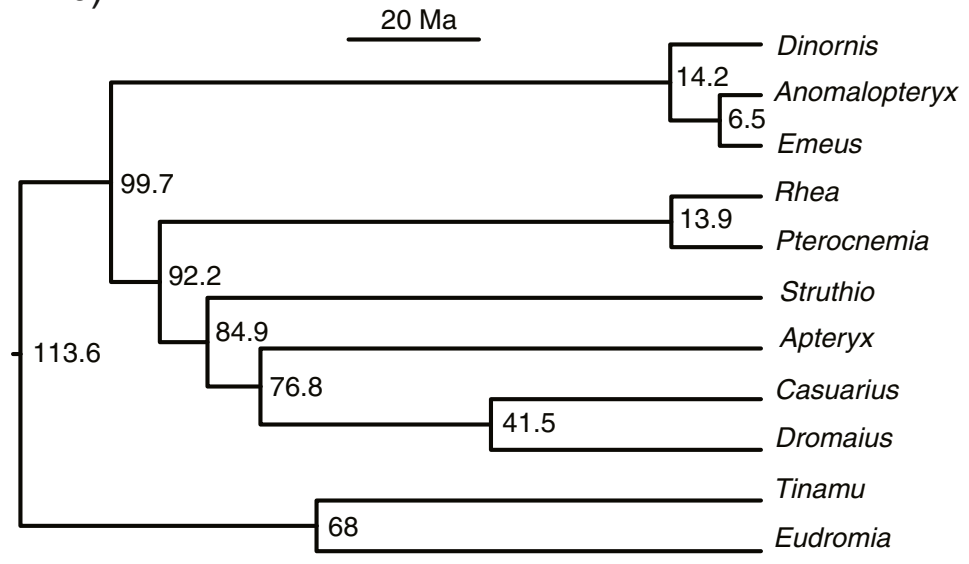

Markov-chain biogeographic model

Time-calibrated phylogeny

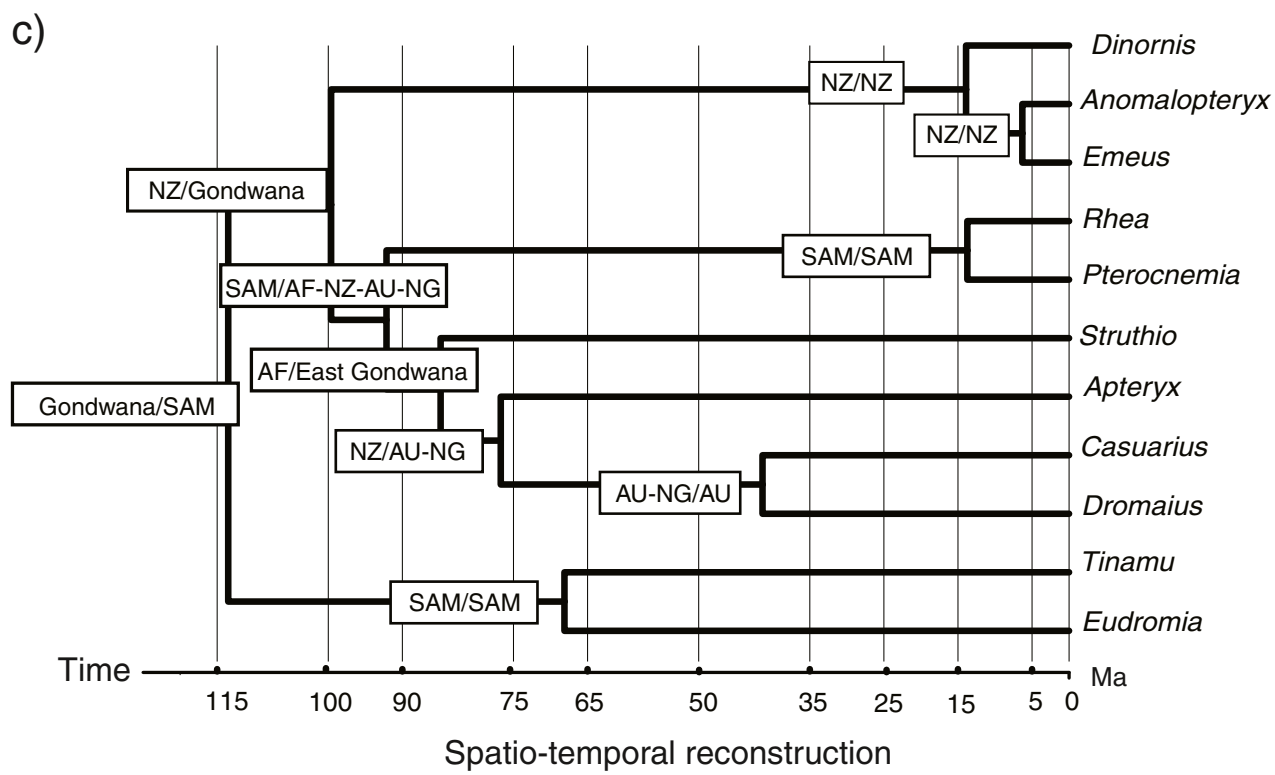

Fig. 4 Parametric, time-based reconstruction of the biogeographic history of ratites. a Range evolution is modeled as a stochastic process ("Markov chain") that evolves along the branches of a phylogeny from ancestor to descendants as a function of time. The Markov process is governed by a matrix of transition probabilities (a) that determines the rate of change between geographic states (here the geographic ranges $\mathrm{A}, \mathrm{B}$, and $\mathrm{AB}$ ), and whose parameters are biogeographic processes such as range expansion $\left(D_{\mathrm{AB}}\right)$ and area-related extinction $\left(E_{\mathrm{A}}\right)$. Given this model (a) and a time-calibrated phylogeny with molecular estimates for lineage divergence times (b, adapted from Pereira and Baker

as in event-based biogeographic methods. There are also additional advantages:

- Rather than considering only the most parsimonious, "minimum change" reconstruction like parsimony, parametric methods can evaluate every possible ancestral area in terms of its "likelihood" (probability) of
2006), it is possible to reconstruct the spatio-temporal evolution of the group (c) by using a parametric biogeographic method such as Dispersal-Extinction-Cladogenesis (Ree et al. 2005). The parametric reconstruction (c) shows the most likely range inheritance scenario at each cladogenetic event; that is, how the ancestral range became divided between the two descendants at speciation; for example, "NZ/Gondwana" indicates diversification within New Zealand when this area was still part of East Gondwana (formed by AFR, NZ, SAM, AUS, and NG), while "NZ/AUS-NG" indicates vicariance between NZ and Australia-New Guinea. Abbreviations as in Fig. 1

explaining the data. Therefore, they are better in integrating the uncertainty in the reconstruction of ancestral ranges in the phylogeny ("mapping uncertainty"). In addition, Bayesian parametric approaches can estimate the parameters over every possible tree topology and combination of branch lengths, so they can account for the uncertainty associated 
with the phylogenetic inference itself ("phylogenetic uncertainty").

- Parametric methods also provide an appropriate statistical approach to compare alternative biogeographic hypotheses or scenarios. Each scenario is formulated in terms of different parametric models, which can be compared on the basis of how well they fit the data. Because the parameters of each alternative model are biogeographic processes, one can identify the processes that best explain the biogeographic patterns by identifying the "best-fitting" model, for example, by using likelihood-based statistical tests. This contrasts with the use of random permutation tests in event-based biogeography, in which observed patterns can only be compared with those expected by chance (Fig. 3d).

- The most important advantage of parametric methods is their ability to integrate into the biogeographic inference estimates of the evolutionary divergence between lineages or the time since cladogenesis, which are represented by the length of branches in the phylogeny (Fig. 4b). For example, Fig. 4c shows that the giant moas of New Zealand diverged from the other ratites in the Early Cretaceous, when New Zealand was still part of Gondwana. In contrast, kiwis and African ostriches (Struthio) are of more recent origin (Late Cretaceous), when Africa and New Zealand had begun to rift apart from Antarctica and Australia. Since these are flightless birds, it raises the intriguing possibility that their ancestors could fly and lost this ability to adapt to the new insular environments, once the southern continents became isolated by oceans.

Parametric methods are still in their infancy and only a few approaches have been developed (see Ree and Sanmartín 2009; Sanmartín 2010 for a review). The most popular is the Dispersal-Extinction-Cladogenesis (DEC) likelihood model developed by Richard Ree and colleagues (Ree et al. 2005; Ree and Smith 2008). This allows estimating by maximum likelihood rates of range expansion (dispersal) and contraction (extinction), and range inheritance scenarios at cladogenetic events from a time-calibrated phylogeny with terminal lineage distributions (Ree and Smith 2008). The second method is the Bayesian island biogeography (BIB) model developed by Sanmartín et al. (2008), which uses Bayesian inference to estimate areas' carrying capacities and rates of dispersal between islands from phylogenetic and distributional data of multiple co-distributed groups. It can be used to infer general biogeographic patterns by using a Bayesian approach that accommodates for differences in age, evolutionary rate, and dispersal capability across lineages (Sanmartín 2010). This approach has recently been used in continental biogeography to infer rates of biotic exchange between ecological and geographically isolated regions in Africa (Sanmartín et al. 2010).
As with event-based methods, parametric methods have been criticized for their reliance on a particular biogeographic model, which is seen as a limitation. Biogeographical models, however, are best seen not as constraints over the data but as alternative hypotheses to explain the data (Sanmartín et al. 2008). A more important limitation is how to balance the complexity of biogeographic models with the inferential power of the method (Ree and Sanmartín 2009). The number of possible ranges and parameters to estimate increases with the number of areas (Fig. 4a), so it is important to think carefully about the model; i.e., the more parameters in the transition probability matrix, the less data available to estimate each parameter. One advantage of the parametric approach is that one can make use of alternative sources of evidence to decrease the size of the parameter matrix. For example, one can disallow certain ancestral ranges based on biological implausibility, e.g., areas that are not geographically adjacent. Another possibility is to disallow certain transitions between geographic states. An advantage of parametric approaches over parsimony-based methods is that they allow external evidence other than the tree topology and lineage distributions to inform the biogeographic model. This can be done by either adding new parameters to the transition matrix, or by scaling a global dispersal or extinction rate according to abiotic factors like geographic distance, the availability of land connections, or the strength of wind and ocean currents (Buerki et al. 2011). For example, in island systems like the Canary Islands, one may wish to constrain dispersal to follow the island chain by making the rate of dispersal between non-adjacent islands in the chain equal to zero (Sanmartín et al. 2008). Whether these constraints are biologically realistic or not depends on each particular scenario.

Finally, a present limitation of the parametric approach is that it assumes that range evolution is uncoupled with lineage diversification. In parametric methods, range evolution is modeled as a process that evolves along the branches of a phylogenetic tree, but the biogeographic model itself does not influence the birth-extinction stochastic process that determines tree growth, branch lengths, and topology (Ree and Sanmartín 2009). Yet some studies have demonstrated that dispersal into new areas can lead to an increase in the rate of diversification (e.g., Moore and Donoghue 2007), which suggests that there is a relationship between the rate of cladogenesis and biogeographic evolution. Goldberg et al. (2011) recently expanded the DEC model of Ree et al. to incorporate range-dependent diversification, in which speciation and extinction parameters are dependent on the size of ancestral geographic ranges; for example, widespread ancestral lineages would have a higher rate of allopatric speciation and a lower rate of extinction than ancestral lineages endemic to a single area. These methods hold great promise, but even the simplest implemented two-area models are parameter-rich (Goldberg et 
al. 2011), and the inferential power of more complex multiplearea models remains to be tested.

\section{Integrating Ecological Processes: Ecological Vicariance and Niche Modeling}

Integrating ecological processes into the reconstruction of biogeographic scenarios has been a long-term aim in historical biogeography (Morrone and Crisci 1995). But until recently there has been no real effort to combine these two aspects of the discipline into a common analytical framework. This has become possible through the development of ecological niche modeling techniques (ENMs). According to the concept of niche conservatism (Wiens 2004; Wiens and Donoghue 2004), lineages tend to conserve their ecological niche through time, the set of environmental conditions in which lineages can reproduce and maintain viable populations. Vicariance is considered the outcome of any environmental change that causes a division in a species geographic range (Wiens 2004). ENMs (Peterson et al. 1999; Kozak et al. 2008) use the association between distribution data (species occurrences) and environmental variables (e.g., temperature, precipitation) to predict the range within which a species could occur. Assuming that niches are preserved over time ("niche conservatism"), and given information about past climates, one can project back the ecological niche for different points in time to reconstruct past species distribution patterns (Yesson and Culham 2006), or to find areas that were in the past within the environmental tolerance of the species and could have acted as dispersal corridors across regions that are now uninhabitable (Weaver et al. 2006). Smith and Donoghue (2010) were the first to combine parametric biogeographic methods with paleoclimate data and ecological niche models of extant taxa as a way to understand how past climates and land connections have shaped the biogeographic distribution of lineages over time. Similarly, Stigall and Lieberman $(2005,2006)$ pioneered the integration of ENM models into paleobiogeographic analysis, through the combination niche models with the fossil record of extinct lineages (e.g., Maguire and Stigall 2009). The advantage of this approach over ENM models based on extant taxa (Smith and Donoghue 2010) is that fossil-based ENM reconstructions do not assume that ecological niches are stable over time (this might be true for ecological time scales but not over geological scales of millions of years), so these models can be used to track patterns of niche conservatism and evolution over longer time scales (Stigall 2012).

\section{Conclusions}

The current biodiversity crisis and the urgent need to decide what to preserve have led to a new surge of interest in biogeographic studies that attempt to understand the evolutionary origin of lineages and historical assembly of biotas. Only by understanding how and where lineages diversified, can we infer how they will respond to future climate and habitat changes (Linder 2005). As reviewed in this article, biogeographers have now an exciting new set of tools with which to address evolutionary questions beyond where and when lineages diversified. This has been driven by the advent of molecular systematics and the development of new methods able to integrate multiple sources of evidence into biogeographic inference: lineage divergence times, paleogeographic and paleoclimatic information, or the ecological niche of lineages. For ratites, this has led to a rethinking of their evolutionary history: "perhaps ancient ratites were able to fly." The new challenges for biogeography lie in the understanding of little-explored areas, such as the marine realm (Barber and Bellwood 2006), or of small-size (microscopic) organisms such as protists, mosses, or lichens, for which dispersal is assumed to be rampant (Fontaneto 2012).

Acknowledgments I am grateful to Prof. Bruce S. Lieberman for the invitation to write this review, which has benefited from the suggestions, comments, and discussion with many colleagues and students over the years. I also thank two anonymous reviewers for their insightful comments. This work has been funded by the Spanish Ministry of Science and Technology (CGL2009-13322-C03-01) and by the National Evolutionary Synthesis Center (NESCent) through grant US NSF \#EF-0423641.

\section{References}

Avise JC. Phylogeography: the history and formation of species. Cambridge, Mass: Harvard University Press; 2000.

Barber PH, Bellwood DR. Biodiversity hotspots: evolutionary origins of biodiversity in wrasses (Halichoeres: Labridae) in the Indo-Pacific and new world tropics. Mol Phylogenet Evol. 2005;35:235-53.

Brooks DR. Parsimony analysis in historical biogeography and coevolution: methodological and theoretical update. Syst Zool. 1990;39:14-30.

Brooks DR. Historical biogeography in the age of complexity: expansion and integration. Rev Mex Biodivers. 2005;76:79-94.

Brundin L. Transantarctic relationships and their significance, as evidenced by chironomid midges: with a monograph of the subfamilies Podonominae and Aphroteniinae and the Austral Heptagyiae. Kungl Svens Vetenskapakad Handl. 1966;11:1-472.

Buerki S, Forest F, Alvarez N, Nylander JAA, Arrigo N, Sanmartín I. An evaluation of new parsimony-based versus parametric inference methods in biogeography: a case study using the globally distributed plant family Sapindaceae. J Biogeogr. 2011;38:53150 .

Cook LG, Crisp MD. Not so ancient: the extant crown group of Nothofagus represents a post-Gondwanan radiation. Proc R Soc Lond B. 2005;272:2535-44.

Cox CB, Moore PD. Biogeography: an ecological and evolutionary approach. 8th ed. Hoboken, NJ: Wiley; 2010.

Crisci JV, Cigliano MM, Morrone JJ, Roig-Juñent S. Historical biogeography of southern South America. Syst Zool. 1991;40:152-71.

Crisci J, Katinas L, Posadas P. Historical biogeography: an introduction. Cambridge: Harvard University Press; 2003. 
Crisp MD, Trewick SA, Cook LG. Hypothesis testing in biogeography. Trends Ecol Evol. 2011;26:66-72.

Croizat L. Panbiogeography. Volumes 1, 2a, 2b. Caracas, Venezuela: Published by the author; 1958 .

Croizat L, Nelson G, Rosen DE. Centers of origin and related concepts. Syst Zool. 1974;31:291-304.

Darlington PJ. Zoogeography: the geographical distribution of animals. New York: Wiley; 1957.

Darwin C. On the origin of species by means of natural selection or the preservation of favored races in the struggle for life. London: John Murray; 1859.

de Queiroz A. The resurrection of oceanic dispersal in historical biogeography. Trends Ecol Evol. 2005;20:68-73.

Donoghue MJ, Moore BR. Toward an integrative historical biogeography. Integr Comp Biol. 2003;43:261-70.

Donoghue MJ, Smith SA. Patterns in the assembly of temperate forests around the Northern Hemisphere. Philos Trans R Soc London Biol. 2004;359:1633-44.

Drummond AJ, Rambaut A. Beast: Bayesian evolutionary analysis by sampling trees. BMC Evol Biol. 2007;7:214.

Ebach MC, Humphries CJ, Williams DM. Phylogenetic biogeography deconstructed. J Biogeogr. 2003;30:1285-96.

Fontaneto D. Biogeography of small organisms: is everything small everywhere? Cambridge, MA: Cambridge University Press; 2012. 365 pages.

Funk VA, Wagner WL. Biogeographical patterns in the Hawaiian Islands. In: Wagner WL, Funk VA, editors. Hawaiian biogeography: evolution on a hot spot archipelago. Washington, DC: Smithsonian Institution; 1995. p. 379-419.

Goldberg E, Lancaster LT, Ree RH. Phylogenetic inference of reciprocal effects between geographic range evolution and diversification. Syst Biol. 2011;60:451-65.

Heads M. Dating nodes on molecular phylogenies: a critique of molecular biogeography. Cladistics. 2005;21:62-78.

Hennig W. Phylogenetic systematics. Chicago: University of Illinois Press; 1966. Translated by D. Dwight Davis and Rainer Zangerl.

Ho SYW. Calibrating molecular estimates of substitution rates and divergence times in birds. J Avian Biol. 2007;38:409-14.

Humboldt A von. Essai sur la géographie des plantes : accompagné d'un tableau physique des régions équinoxiales, fondé sur des mesures exécutées, depuis le dixième degré de latitude boréale jusqu'au dixième degré de latitude australe, pendant les années 1799, 1800, 1801, 1802 et 1803; 1805.

Humphries CJ, Parenti L. Cladistic biogeography. Oxford: Clarendon; 1986.

Humphries CJ, Parenti L. Cladistic biogeography. 2nd ed. New York: Oxford University Press; 1999.

Kodandaramaiah U. Use of dispersal-vicariance analysis in biogeography - a critique. J Biogeogr. 2010;37:3-11

Kozak KH, Graham CH, Wiens JJ. Integrating GIS-based environmental data into evolutionary biology. Trends Ecol Evol. 2008;23: $141-8$.

Lieberman BS. Paleobiogeography. New York: Plenum/Kluwer Academic; 2000.

Lieberman BS. Phylogenetic biogeography with and without the fossil record: gauging the effects of extinction and paleontological incompleteness. Palaeogeogr Palaeoclimatol Palaeoecol. 2002;178:39-52.

Lieberman BS. Paleobiogeography: the relevance of fossils to biogeography. Annu Rev Ecol Evol Syst. 2003;34:51-69.

Lieberman BS, Eldredge N. Trilobite biogeography in the Middle Devonian: geological processes and analytical methods. Paleobiology. 1996;22:66-79.

Linder HP. Evolution of diversity: the Cape Flora. Trends Plant Sci. $2005 ; 10: 536-41$

Lomolino MV, Riddle BR, Whittaker RJ, Brown JH. Biogeography. 3rd ed. Sunderland, Mass: Sinauer Associated, Inc; 2006.
Maguire KC, Stigall AL. Paleobiogeography of Miocene Equinae of North America: a phylogenetic biogeographic analysis of the relative roles of climate, vicariance, and dispersal. Palaeogeogr Palaeoclimatol Palaeoecol. 2008;267:175-84.

Maguire KC, Stigall AL. Using ecological niche modeling for quantitative biogeographic analysis: a case study of Miocene and Pliocene Equinae in the Great Plains. Paleobiology. 2009;35:587611.

Matthew WD. Climate and evolution. Ann Acad Sci NY. 1915;24:171318.

Moore BR, Donoghue MJ. Correlates of diversification in the plant clade dipsacales: geographic movement and evolutionary innovations. Am Nat. 2007;170:S28-55.

Morrone JJ. Evolutionary biogeography. An integrative approach with case studies. New York: Columbia University Press; 2009.

Morrone JJ, Crisci JV. Historical biogeography: introduction to methods. Annu Rev Ecol Syst. 1995;26:373-401.

Nelson G, Ladiges PY. Paralogy in cladistic biogeography and analysis of paralogy-free subtrees. Am Mus Novit. 1996;3167:1-58.

Nelson G, Platnick NI. Systematics and biogeography: cladistics and vicariance. New York: Columbia University Press; 1981.

Nylander JAA, Olsson U, Alstrom P, Sanmartín I. Accounting for phylogenetic uncertainty in biogeography: a Bayesian approach to dispersal-vicariance analysis of the thrushes (Aves: Turdus). Syst Biol. 2008;57:257-68.

Page RDM. Component analysis: a valiant failure? Cladistics. 1990;6:119-36.

Page RDM. Maps between trees and cladistic analysis of historical associations among genes, organisms, and areas. Syst Biol. 1994;43:58-77.

Page RDM. Parallel phylogenies: reconstructing the history of hostparasite assemblages. Cladistics. 1995;10:155-73.

Parenti L. Common cause and historical biogeography. In: Ebach MC, Tangney RS, editors. Biogeography in a changing world. Boca Raton, California: CRC Press-Taylor and Francis Group; 2007. p. 61-71.

Pereira SL, Baker AJ. A mitogenomic timescale for birds detects variable phylogenetic rates of molecular evolution and refutes the standard molecular clock. Mol Evol Biol. 2006;23:1731-40.

Peterson AT, Soberón J, Sanchez-Cordero V. Conservatism of ecological niches in evolutionary time. Science. 1999;285:1265-7.

Platnick NI, Nelson G. A method of analysis for historical biogeography. Syst Zool. 1978;27:1-16.

Pole M. Can long-distance dispersal be inferred from the New Zealand plant fossil record? Aust J Bot. 2001;49:357-66.

Prieto-Márquez A. Global historical biogeography of hadrosaurid dinosaurs. Zool J Linn Soc. 2010;159:503-25

Ree RH, Sanmartín I. Prospects and challenges for parametric models in historical biogeographic inference. J Biogeogr. 2009;36:1211-20.

Ree RH, Smith SA. Maximum likelihood inference of geographic range evolution by dispersal, local extinction, and cladogenesis. Syst Biol. 2008;57:4-14.

Ree RH, Moore BR, Webb CO, Donoghue MJ. A likelihood framework for inferring the evolution of geographic range on phylogenetic trees. Evolution. 2005;59:2299-311.

Renner S. Plant dispersal across the tropical Atlantic by wind and sea currents. Int J Plant Sci. 2004;165(4 Suppl):S23-33.

Ronquist F. Manual DIVA v.1.1. Computer program for MacOS and Win32. http://diva.sourceforge.net/1996.

Ronquist F. Dispersal-vicariance analysis: a new approach to the quantification of historical biogeography. Syst Biol. 1997;46:195-203.

Ronquist F. Phylogenetic approaches in coevolution and biogeography. Zool Scr. 1998;26:312-22.

Ronquist F. Parsimony analysis of coevolving associations. In: Page RDM, editor. Tangled trees. Phylogeny, cospeciation, and coevolution. Chicago, IL: University of Chicago Press; 2003. p. 22-64. 
Ronquist F, Sanmartín I. Phylogenetic methods in biogeography. Annu Rev Ecol Evol Syst. 2011;42:441-64.

Rosen DE. Vicariant patterns and historical explanation in biogeography. Syst Zool. 1978;27:159-88.

Sanmartín I. Event-based biogeography: integrating patterns, processes, and time. In: Ebach MC, Tangney RS, editors. Biogeography in a changing world. Boca Raton, California: CRC Press-Taylor and Francis Group; 2007. p. 135-59.

Sanmartín I. Dispersal versus vicariance. In: McGraw-Hill Yearbook of Science and Technology. New York: McGraw-Hill; 2009. p. 85-8.

Sanmartín I. Breaking the chain of parsimony: parametric approaches in historical biogeography. In: Cox CB, Moore PD, editors. Biogeography, an ecological and evolutionary approach. 8th ed. Hoboken NJ: Wiley; 2010. p. 213-4.

Sanmartín I. A paleogeographic history of the Southern Hemisphere. Available at DIGITAL CSIC: http://hdl.handle.net/10261/34831. 2002. Accessed 14 Nov 2011.

Sanmartín I, Ronquist F. Southern Hemisphere biogeography inferred by event-based models: plant versus animal patterns. Syst Biol. 2004;53:216-43.

Sanmartín I, Enghoff H, Ronquist F. Patterns of animal dispersal, vicariance and diversification in the Holarctic. Biol J Linn Soc. 2001;73:345-90.

Sanmartín I, Wanntorp L, Winkworth RC. West Wind Drift revisited: testing for directional dispersal in the Southern Hemisphere using event-based tree fitting. J Biogeogr. 2007;34:398-416.

Sanmartín I, van der Mark P, Ronquist F. Inferring dispersal: a Bayesian approach to phylogeny-based island biogeography, with special reference to the Canary Islands. J Biogeogr. 2008;35:428-49.

Sanmartín I, Anderson CL, Alarcón-Cavero ML, Ronquist F, Aldasoro JJ. Bayesian island biogeography in a continental setting: the Rand Flora case. Biol Lett. 2010;6:703-7.

Simpson GC. Evolution and geography. Eugene, OR: Oregon State University of Higher Education; 1953.

Simpson GC. Splendid isolation: the curious history of mammals in South America. New Haven CT: Yale University Press; 1980.
Smith SA, Donoghue MJ. Combining historical biogeography with niche modeling in the Caprifolium clade of Lonicera (Caprifoliaceae, Dipsacales). Syst Biol. 2010;59:322-41.

Stigall AL. Using ecological niche modeling to evaluate niche stability in deep time. J Biogeogr. 2012;39:772-81.

Stigall AL, Lieberman BS. Using environmental niche modeling to study the Late Devonian biodiversity crisis. In: Over DJ, Morrow JR, Wignall PB, editors. Understanding the Late Devonian and Permian-Triassic biotic and climatic events: towards an integrated approach. Developments in paleontology and stratigraphy. Amsterdam: Elsevier; 2005. p. 93-180.

Stigall AL, Lieberman BS. Quantitative palaeobiogeography: GIS, phylogenetic biogeographical analysis, and conservation insights. J Biogeogr. 2006;33:2051-60.

Upchurch P, Hunn CA. Time: the neglected dimension in cladistic biogeography. Geobios. 2002;35:277-86.

Wallace AR. The Geographical Distribution of Animals. London: Macmillan. 1876.

Weaver KF, Anderson T, Guralnick R. Combining phylogenetic and ecological niche modeling approaches to determine distribution and historical biogeography of Black Hills mountain snails (Oreohelicidae). Divers Distrib. 2006;12:756-66.

Wiens JJ. Speciation and ecology revisited: phylogenetic niche conservatism and the origin of species. Evolution. 2004;58:193-7.

Wiens JJ, Donoghue MJ. Historical biogeography, ecology and species richness. Trends Ecol Evol. 2004;19:639-44.

Wiley EO. Phylogenetic systematics and vicariance biogeography. Syst Zool. 1988;37:271-90.

Wojciki M, Brooks DR. PACT: an efficient and powerful algorithm for generating area cladograms. J Biogeogr. 2005;32:755-74.

Woodburne MO, Case JA. Dispersal, vicariance, and the late Cretaceous to early Tertiary land mammal biogeography from South America to Australia. J Mamm Evol. 1996;3:121-61.

Yesson C, Culham A. Phyloclimatic modeling: combining phylogenetics and bioclimatic modeling. Syst Biol. 2006;55:785802 . 